\title{
O MOVIMENTO INGLÊS ARTS AND CRAFTS E A ARQUITETURA NORTE-AMERICANA
}

\section{Ana Tagliari \\ Haroldo Gallo \\ Instituto de Artes - UNICAMP \\ O movimento inglês Arts and Crafts}

A base da estética moral do Arts and Crafts foi criada pelo arquiteto e teórico A.W.N. Pugin (1812-1852), que em seus livros deixou a herança que deu origem ao movimento. Pugin queria reunificar o papel do artista e artesão como acontecia na Idade Média. Defensor dos princípios da arte gótica, assim como seu contemporâneo Eugène Viollet-le-Duc, Pugin escreveu as três regras básicas que deveriam ser seguidas pela nova arquitetura:

1. Honestidade na estrutura e no uso e aplicação dos materiais;

2. Originalidade no projeto, portanto sem imitações estilísticas;

3. Uso de materiais regionais preservando suas propriedades e suas cores.

Inspirado pelas idéias de Pugin, John Ruskin (1819-1900) deixou como legado para o movimento inglês As Pedras de Veneza (sendo um dos capítulos intitulado The Nature of Gothic (1853)). Os escritos de Ruskin pregavam a natureza como inspiração e instrução para os artistas e arquitetos, influenciando William Morris, o líder do Arts and Crafts. Ruskin era contra a divisão do trabalho na era capitalista e defendia o trabalho artesanal e uso de materiais naturais. ${ }^{1}$

Alguns artistas do Arts and Crafts lutavam por reformas sociais por meio das artes. Ironicamente o movimento teve sucesso apenas entre grandes e ricos industriais, os quais podiam pagar pelos serviços mais exclusivos destes artistas e arquitetos. É importante ressaltar que Morris era contra o uso de máquinas e a industrialização no processo de construção das obras de arte. Entretanto, o ideal anti-industrial encarecia o objeto, visto que este era feito apenas por uma pessoa do começo ao final. Nota-se

\footnotetext{
Outro importante legado desses teóricos e estetas foi a teoria do restauro, a forma sistematizada de abordar a pré-existência, pois a contraposição de suas posições, intervencionista em Le Duc e conservadora em Ruskin, continuam ainda hoje sendo pontos de partida para a abordagem da questão da preservação.
} 
que o movimento não obteve sucesso total de suas aspirações diante dos avanços tecnológicos.

Os quatro princípios que norteavam o movimento do Arts and Crafts eram:

1. unidade na composição artística;

2. valorização do trabalho artesanal;

3. individualismo e regionalismo.

Após a Revolução Industrial houve uma desvalorização do trabalho do artesão e o objetivo do Arts and Crafts era de restabelecer este valor, a harmonia entre o trabalho do arquiteto, designer e artesão, e de realizar objetos de arte de uso cotidiano para todos.

$\mathrm{Na}$ arquitetura o edifício deveria ser construído com materiais locais, desenhados para se moldar à paisagem e refletir uma construção tradicional e vernacular. A unidade da construção deveria ser alcançada por meio da união de desenhos e linguagens da estrutura até o mobiliário de maneira simples e honesta, ou seja, sem revestimentos que escondessem a beleza e coloração inerente ao material natural.

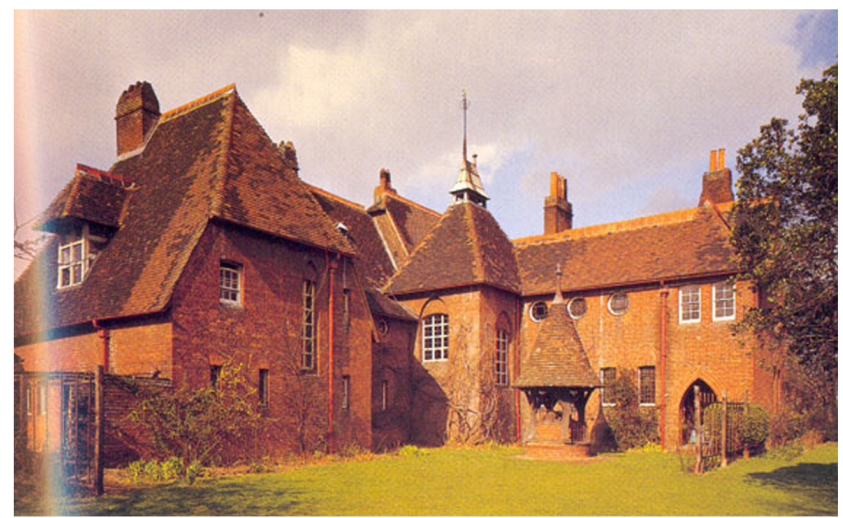

Figura 01 - Red House - Upton, Kent - 1859-60. Arquiteto Philip Webb Fonte: CUMMING, 1991.

A primeira residência considerada pertencente ao movimento Arts and Crafts foi a Red House (1859-60), em Upton, Kent, projetada por Philip Webb (1831-1915) para a família de William Morris.

A Red House, que tem este nome devido à coloração do tijolo usado, foi construída com base num método de construção tradicional local e exerceu certa influência na arquitetura das próximas décadas. Desde o 
material utilizado até suas formas e estrutura, a Red House se diferencia das construções feitas na época e local. Webb não desejava que a residência fosse enquadrada em nenhum estilo, mas sim nos princípios comuns do movimento, que eram funcionalismo (quando a forma decorre do desempenho da função), relação do edifício com a paisagem e seleção dos materiais.

Webb seguiu as recomendações de Pugin e de Ruskin, segundo as quais o edifício deveria ser a reflexão honesta dos materiais utilizados e cuidadosa relação com a paisagem. Pugin também alertava para o fato de que o edifício não deveria ter características comuns a outros projetados pelo mesmo arquiteto ou por uma determinada Escola (que caracterizasse um estilo), o que poderia enquadrá-lo em normas a serem seguidas, e que conduziria à fuga dos princípios do regionalismo e individualismo pregados por ele. Segundo Pugin, a arquitetura deveria ter variações de acordo com a região e os usuários.

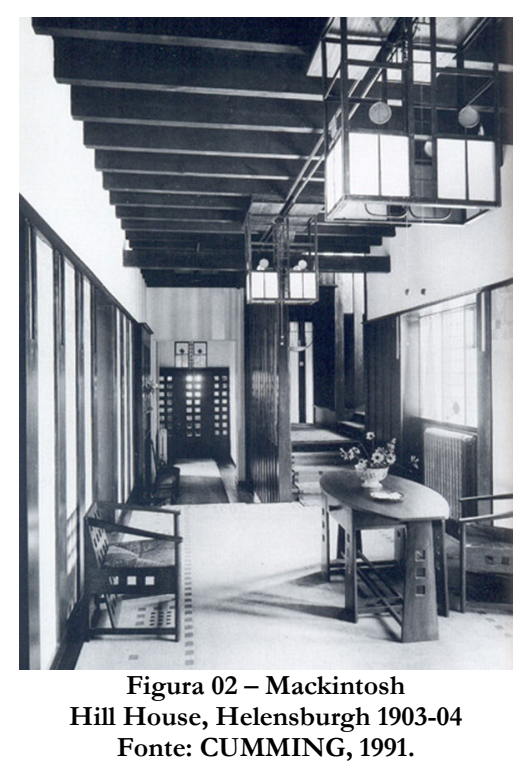




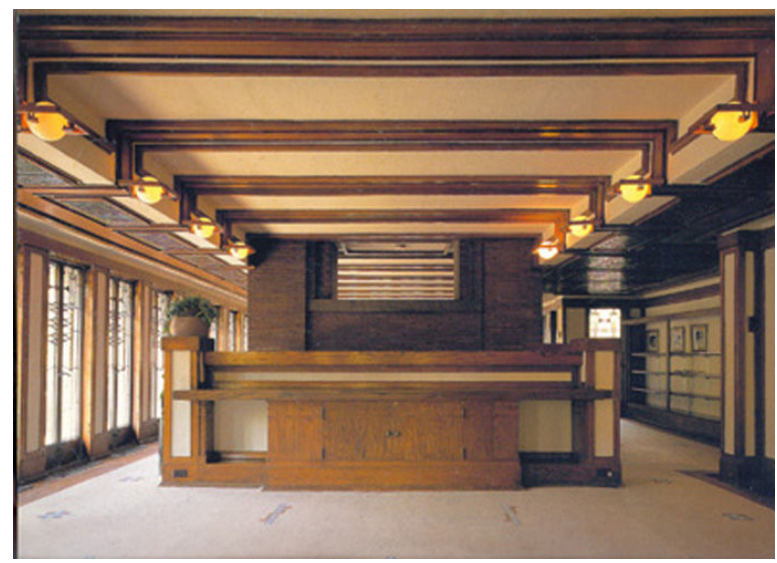

Figura 03 - Frank Lloyd Wright

Robie House, Chicago - 1906

Fonte: HILDEBRAND, 1991.

Charles Rennie Mackintosh (1868-1928) foi o arquiteto que levou ao extremo a idéia de unidade na arquitetura Arts and Crafts. Ele projetava todos os detalhes da residência, desde frisos em materiais da fachada até tapetes, floreiras, luminárias e cinzeiros.

Para o arquiteto, o interior da residência tinha que refletir a maneira de viver de seus

habitantes. No entanto, segundo Cumming ${ }^{2}$, diferentemente dos outros arquitetos do movimento, Mackintosh não dava tanta importância para um bom acabamento na feitura do mobiliário, o que resultava num trabalho relativamente mal acabado.

Os interiores das residências de Mackintosh são muito semelhantes aos de Wright, em sua fase inicial, e Nikolaus Pevsner ${ }^{3}$ considera Mackintosh como o equivalente inglês a Wright.

\section{Século XIX e XX: Relação do movimento inglês com a arte e arquitetura nos Estados Unidos}

A idéia de que cada país deve possuir sua própria arquitetura que reflita sua história particular, geografia e clima, era central para o movimento do Arts and Crafts. Nos Estados Unidos, o extenso e diverso território geográfico permitiu vários tipos de arquitetura vernacular. Na região de Illinois, as planas pradarias eram a inspiração, enquanto na Califórnia eram o mar, o

2 CUMMING, E. e KAPLAN, W. The Arts and Crafts Movement. London: Thames and Hudson Ltd, 1991. p.55.

3 PEVSNER, Nikolaus. Os Pioneiros do Desenho Moderno: De William Morris a Walter Gropius; São Paulo: Martins Fontes. 1994. p.167. 
sol e o clima tropical. Como notou Bruno Zevi ${ }^{4}$, para entender a verdadeira contribuição da arquitetura norte-americana, devemos considerar seus edifícios residenciais e não apenas seus famosos arranha-céus, posição que endossamos, uma vez que essa reflete a identidade do lugar.

$\mathrm{Na}$ região da Califórnia, no período de 1907-09, a arquitetura considerada muito próxima aos princípios do Arts and Crafts foi a dos Bungalows. Segundo Clay Lancaster ${ }^{5}$, Bungalow foi o termo utilizado para designar pequenos lares norte-americanos entre os anos de 1880 a 1930.

O Bungalow era a residência democraticamente correta, pois seu custo era baixo e acessível a todos os cidadãos. Caracterizada como uma construção californiana pelas qualidades espaciais, espaços interiores amplos e abertos, um pavimento, grandes beirais que protegiam do sol e uso intenso de materiais naturais como a madeira e uso de técnicas tradicionais na construção, o Bungalow passava uma imagem de informalidade típica da sociedade californiana, com grande mobilidade, transitória, open-mind e pronta para mudanças. O Bungalow era uma residência feita de madeira, influenciada pelas técnicas tradicionais de construção americanas, o Ballon Frame ${ }^{6}$. A característica visual do Bungalow dava uma impressão de leveza e de fácil montagem.

No centro-oeste dos Estados Unidos, a arquitetura que englobou esse tipo de postura foi a orgânica. Em meados do século XIX, o arquiteto Louis Sullivan (1856-1924), inspirado na arquitetura funcional de Henry H. Richardson e William Le Baron Jenney, realizou uma arquitetura livre de ornamentos, com nova tecnologia e funcional. Sua célebre frase "A Forma segue a função" resume sua postura com relação à questão estética.

\footnotetext{
4 "To see what America has really given to architecture we must consider its domestic buildings and not its skyscrapers". ZEVI, Bruno. Towards an Organic Architecture. London: Faber \& Faber Limited, 1949. p.120.

5 LANCASTER, Clay. The American Bungalow. The Art Bulletin, Vol.40, No.3. (Set.1958), p239.

6 O Ballon Frame é um método de construção leve com madeira, tradicional dos Estados Unidos.
} 


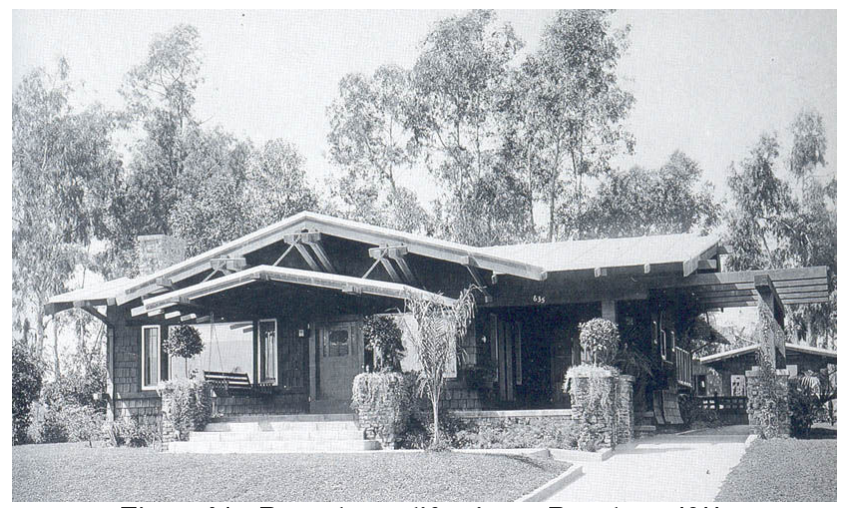

Figura 04 - Bungalow californiano - Pasadena, 1911.

Arquiteto Arthur S. Heineman.

Fonte: CUMMING, 1991.

Considerado um arquiteto de vanguarda, Sullivan era uma pessoa muito culta e consciente dos acontecimentos artísticos da Europa. Foi o mentor e líder filosófico do grupo de arquitetos que desenvolveram a arquitetura orgânica e original no centro-oeste americano, a Prairie School. O ideal orgânico, instaurado por Sullivan a partir da década de 1880, tinha o objetivo de depurar ornamentos e de criar uma arquitetura que crescesse de acordo com a necessidade de seus usuários.

Frank Lloyd Wright (1867-1959) trabalhou no escritório de Sullivan por alguns anos e em 1893 abriu seu próprio estúdio em Oak Park, região do subúrbio de Chicago. $\mathrm{O}$ arquiteto foi o grande disseminador das idéias de Sullivan na arquitetura residencial, e em seus livros se refere a ele com muito respeito, chamando-o de grande Mestre.

Wright se tornou um dos mais importantes arquitetos norteamericano do século XX, e é conhecido pela arquitetura orgânica que desenvolveu principalmente na área residencial. A arquitetura orgânica para Wright, é uma arquitetura concebida de acordo com o local específico e com as necessidades individuais de seus habitantes, uma arquitetura "para o homem".

Como observou Bruno Zevi ${ }^{7}$, Wright proporcionou uma nova arquitetura residencial aos norte-americanos. Comparando-se com o que vinha sendo feito, Wright adaptou e desenvolveu as idéias de arquitetura

\footnotetext{
7 “(...) a arquitetura wrightiana propõe na América um caminho alternativo. O objetivo: criar um novo gosto no americano médio, elevando o padrão qualitativo da arquitetura residencial'. ZEVI, Bruno. Frank Lloyd Wright. Barcelona: Gustavo Gili S.A.,1985. p.41
} 
orgânica de Sullivan na concepção de espaços residenciais. Além de romper com tipologias da arquitetura que vinha sendo desenvolvida na região, uma de suas grandes inovações esteve relacionada aos espaços internos, que se tornaram mais amplos e sem divisões rígidas, depurando as formas arquitetônicas, como notou Vilanova Artigas ${ }^{8}$. Wright se preocupou com a criação de espaços integrados com a natureza, cuja intenção era promover bem estar e liberdade ao individuo, o que, segundo Wright, ${ }^{9}$ torna o espaço muito mais habitável.

Wright ${ }^{10}$ preconizava o uso honesto dos materiais naturais, ressaltando que suas qualidades inerentes como cores e texturas qualificam a arquitetura moderna. Durante os primeiros anos de sua carreira, sua obra orgânica esteve baseada em 6 princípios, como ele mesmo explica em seu livro The Natural House: simplicidade, plasticidade, continuidade, integridade, gramática e uso de materiais naturais, com o objetivo de conceber um espaço funcional e confortável para seu habitante. Nesse período inicial de sua carreira, conhecido como Prairie houses, Wright projetou a Robie House - 1909 -, considerada por muitos autores e críticos de Wright como sua obra-prima e por outros ainda como a casa emblemática do século XX. Em sua fase madura, após a década de 30, Wright ampliou esse conceito, construindo residências orgânicas de baixo custo, as Usonian Houses.

8 “(...) Assim, a casa norte-americana de Wright perdeu paredes, ligou-se com a paisagem, com o exterior. Confundiu contorno e compartimentos e passou a definir-se pela dinâmica da vida, pela dinâmica da atividade bumana a que se destinava". ARTIGAS, Vilanova. Caminhos da Arquitetura. São Paulo: Cosac \& Naify Edições Ltda., 1999, p.58.

9 "Freedom of floor space (...) worked a miracle in the new dwelling place. A sense of appropriate freedom had changed its whole aspect. The dwelling became more fit for human habitation... and more natural to its site. An entirely new sense of space values in architecture of the modern world'. WRIGHT, Frank Lloyd. An American Architecture. New York: Horizon Press, 1955. p.65.

10 "To be modern simply means that all materials are used honestly for the sake of their qualities, and that the materials modify the design of the building". WRIGHT, Frank Lloyd. An American Architecture. New York: Horizon Press, 1955. p.99. 


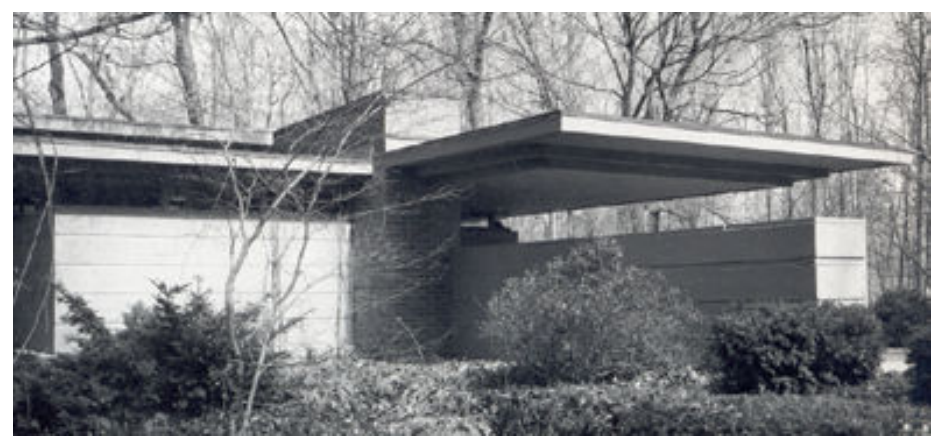

Figura 05 - Usonian House.

Residência Goetsch-Winckler - 1939

Okemos, Michigan

Fonte: PFEIFFER, 1991.

As Usonian Houses apresentam algumas similaridades aos Bungalows construídos na Califórnia no começo do século XX. Ambas são construções em que há o predomínio do material natural e que remetem à tradição vernacular do Ballon-Frame norte-americano, bem como a uma arquitetura vernacular da região.

\section{Características semelhantes entre a Red House de Philip Webb e a arquitetura orgânica residencial Prairie e Usonian de Wright:}

São apontados a seguir pontos de semelhança entre a obra de Webb e a de Wright:

1. Uso de material natural sem revestimento;

2. Simplicidade e diferença dos estilos da época (vitorianos);

3. Desenhos de abstração da natureza usados nos vitrais e tapeçarias;

4. Respeito à natureza circundante;

5. Énfase na assimetria, diferente dos padrões da época;

6. Economia de recursos referentes à construção/ ausência de ornamentos;

7. Concepção de dentro para fora. Crescimento de acordo com necessidades dos habitantes;

8. Espaço projetado com o objetivo de criar uma arquitetura que integra interior e exterior. 


\section{Princípios comuns ao Arts and Crafts e a arquitetura orgânica de Wright}

Semelhanças podem ser notadas entre os princípios da arquitetura orgânica de Frank Lloyd Wright e as idéias do Arts and Crafts, e essas referências programáticas são a seguir apontadas:

1. Unidade das artes: todos os artistas têm seu valor único e juntos podem fazer uma obra completa de qualidade;

2. Valorização do trabalho e do processo de projeto artesanais;

3. Levar arte a todos os cidadãos, principalmente por meio de objetos de uso cotidiano;

4. Uso de materiais naturais e locais, preservando suas características inerentes (cor e textura);

5. No caso da arquitetura, o edifício deveria ser desenhado para fazer parte da paisagem;

6. Simplicidade e honestidade: não esconder as características inerentes dos materiais, como cores e texturas, por meio de revestimentos;

7. Respeito, admiração e inspiração à cultura e arte oriental;

8. Ideais sociais e vontade de mudar a sociedade por meio das artes;

9. Arte individualista, ou seja, concebida e construída especialmente para uma determinada pessoa;

10. Arquitetura vernacular e regionalista: respeito pela cultura local e sua identidade, de preferência localizada longe de aglomerados urbanos;

11. Trazer mudança e ruptura à arte e arquitetura.

12. Realização de uma arte e arquitetura em geral doméstica;

13. Idéia de guilda como na Idade Média: os mestres reuniam seus aprendizes em seus estúdios para passar o conhecimento do oficio;

14. Inspiração em poetas que pregavam a liberdade, democracia, vida simples e natural. (para o Arts and Crafts, Edward Carpenter e para Wright, Walt Whitman).

\section{Características que diferenciam o Arts and Crafts e a arquitetura orgânica de Wright}

Embora haja muitas semelhanças, as diferenças também podem ser notadas. Uma característica que diferenciou Morris e Wright foi a questão do uso da máquina no processo artístico. Como já foi dito, Morris condenava seu uso, mas Wright dizia que se usada de maneira adequada seria um ótimo instrumento para se levar arte a todos os cidadãos. Num 
gesto de crítica e discussão intelectual com o movimento Arts and Crafts, Wright publica em 1901 um célebre artigo intitulado The Art and Craft of the Machine ${ }^{11}$, que causou grande repercussão na época. Neste caso havia um paradoxo com as idéias do Arts and Crafts que pregavam uma valorização do trabalho artesanal.

$\mathrm{Na}$ cultura norte-americana não havia tantas restrições com relação à comercialização da arte e o anti-industrialismo não era algo tão rígido quanto na inglesa. Desta maneira a arquitetura orgânica de Wright atingiu uma grande parte de cidadãos americanos, ao contrário dos ingleses do Arts and Crafts, com seu rígido ideal socialista de que sua arte poderia ser uma ferramenta para a resolução dos problemas da sociedade, independente de todo o sistema e da época em que viviam.

Nas primeiras décadas do século XX, a sociedade americana passava por uma boa situação financeira e com grandes transformações na área industrial e urbana. Enquanto isso, na Inglaterra havia pobreza e a minoria que se enriquecia eram os industriais, odiados por Morris, entretanto, paradoxalmente, seus únicos clientes.

Nas Usonian Houses, Wright realiza uma arquitetura regional, individual, com materiais naturais locais, que dialoga com a paisagem e acessível à maioria dos cidadãos norte-americanos. O que foi somente um ideal romântico do movimento inglês Arts and Crafts, teve sua concretização de maneira bem sucedida nos Estados Unidos. Segundo Argan ${ }^{12}$, Wright une o respeito à natureza, valorização do artesanato, indústria, sabedoria oriental, racionalismo ocidental, tudo para criar uma arquitetura única e inimitável.

\section{Bibliografia}

ARGAN, Giulio Carlo. Arte Moderna. São Paulo: Companhia das Letras,1992.

ARTIGAS, J. B. Vilanova. Caminhos da Arquitetura. São Paulo: Cosac \& Naify Ed.Ltda.,1999.

CUMMING, Elizabeth e KAPLAN, Wendy. The Arts and Crafts Movement. London: Thames and Hudson Ltd, 1991.

${ }^{11}$ The Art and craft of the machine. Artigo publicado no Chicago Arts and Crafts Society, Hull House, 06/03/1901 e no Western Society of Engineers, em 20/03/1901. Republicado na íntegra em: KAUFMANN, Edgar. FLW Writings and Buildings. USA: Meridian Books, 1960. p. 55 à 73.

12 "Para Wright, o edifício é um acontecimento primeiro e único, inimitável e irrepetível". ARGAN, Giulio Carlo. Arte Moderna. São Paulo: Companhia das Letras,1992. p. 418. "Natureza, artesanato, indústria, sabedoria oriental, racionalismo ocidental, tudo concorre e se funde na criação do gênio". ARGAN, Giulio Carlo. Arte Moderna. São Paulo: Companhia das Letras,1992 p. 419. 
HILDEBRAND, G. The Wright Space:Pattern \& Meaning in FLW's Houses. Washington: W.Univ.1991.

KAUFMANN, Edgar. FLWW ritings and Buildings. USA: Meridian Books, 1960.

LANCASTER, Clay. The American Bungalow. The Art Bulletin, Vol.40, No.3. (Set.1958).

PEVSNER, Nikolaus. Os Pioneiros do Desenho Moderno: De William Morris a Walter Gropius; Tradução João Paulo Monteiro. $2^{\circ}$ ed. - São Paulo: Martins Fontes, 1994.

WRIGHT, Frank Lloyd. An American Architecture. New York: Horizon Press, 1955.

ZEVI, Bruno. Frank Lloyd Wright. Barcelona: Gustavo Gili S.A.,1985.

ZEVI, Bruno. Towards an Organic Architecture. London: Faber \& Faber Limited, 1949. 